\title{
Problematizando o estágio supervisionado de inglês
}

\section{Problematizing English teaching practicum}

Nilvânia Damas Silva Lima*

Instituto de Desenvolvimento Tecnológico do Centro-Oeste

Rosane Rocha Pessoa**

UFG

RESUMO: Este estudo objetivou problematizar o estágio supervisionado por meio da identificação de teorias pessoais de quatro professores em formação universitária sobre o ensino de inglês na escola pública. Além disso, procurou-se identificar mudanças em suas teorias pessoais após o estágio supervisionado e o que as deflagraram. Para tanto, utilizaram-se duas entrevistas semiestruturadas e um questionário. Os quatro participantes cursavam o quinto e último ano de Letras na Universidade Federal em Goiás e realizaram o estágio supervisionado na escola pública federal CEPAE/UFG. Os resultados apontaram que os participantes acreditam na eficácia do ensino inglês na escola pública e que o estágio supervisionado realizado em um contexto considerado quase ideal influiu no modo como eles perceberam o ensino de inglês na escola pública.

PALAVRAS-CHAVE: estágio supervisionado, teorias pessoais, ensino de inglês, escola pública.

ABSTRACT: This study aimed at problematizing practicum by means of identifying personal theories of four preservice English teachers about teaching English in public schools. Besides, it was intended to identify changes in their personal theories and what triggered them. Two semi-structured interviews and a questionnaire were used to collect data. The participants were in the fifth and last year of a teacher education course at the Universidade Federal of Goiás and the practicum was conducted in a federal school called CEPAE/UFG. The results showed that the participants believe that it is possible to teach English successfully in public schools. They also show that the practicum, which was conducted in a context considered almost ideal, influenced the trainees' perceptions about teaching in public schools.

KEYWORDS: practicum, personal theories, English teaching, public schools.

* damassilvalima@yahoo.com.br

** pessoarosane@gmail.com 


\section{Introdução}

Ensinar inglês na escola pública não é tarefa fácil, principalmente para professores recém-formados, inexperientes na tarefa de ensinar ou que ainda não conhecem tal contexto. Para esses professores, o período de prática de ensino proporcionado pelo estágio supervisionado se torna o único contato com tal ambiente. Sendo assim, eles idealizam o ensino de inglês nas escolas públicas sob o ponto de vista de alunos oriundos dessas instituições ou sob a ótica de quem já ouviu falar sobre esse contexto.

Percebendo a importância do estágio supervisionado na constituição, reforço ou mudanças nas teorias pessoais desses professores sobre o ensino de inglês na escola pública, objetivamos verificar, neste estudo, se o estágio supervisionado influenciou as teorizaçōes dos participantes sobre a possibilidade de ensinar a língua inglesa nesse contexto. Além disso, buscamos identificar se houve mudanças nessas teorizações ao final do período de realização do estágio. Em caso afirmativo, quais foram os fatores que as deflagraram.

Como o termo "teoria" é utilizado em referência aos conhecimentos dos participantes e dos pesquisadores, torna-se necessário fazer uma distinção entre "teorias pessoais" e "teorias acadêmicas". Para Vieira-Abrahão (2004), as teorias pessoais de um professor referem-se ao conhecimento que o professor traz consigo. Tal conhecimento, segundo Handal e Lauvas (1987 apud ZEICHNER; LISTON, 1996), advém das experiências pessoais como pais, professores ou alunos; do conhecimento transmitido por outros, formal ou informalmente; e dos valores sobre o que é bom ou ruim, certo ou errado no que concerne à vida em geral e mais especificamente à educação. "Teorias acadêmicas" podem ser definidas mais simplesmente como o que os especialistas dizem sobre determinado objeto, assunto ou situação (VIEIRA, 2005).

Neste estudo, entendemos as teorias pessoais de professores de língua inglesa como um conjunto de todo o conhecimento adquirido durante suas vidas, acrescentado de suas experiências de formação acadêmica ou práticas e das relaçôes dialéticas que mantêm com seus pares.

Tendo definido "teorias pessoais" e buscando cumprir os objetivos propostos, apresentaremos alguns estudos sobre a formação de professores de inglês e a realização do estágio supervisionado, com o intuito de problematizar este último. Logo após, tendo por base pesquisas que tratam do ensino de língua inglesa em escolas públicas, trataremos de sua possibilidade. 


\section{Formação de professores de língua inglesa e estágio supervisionado}

O estágio supervisionado caracteriza-se como um momento de extrema importância na e para a formação do profissional docente, pois propicia, aos professores em formação que ainda não exercem a profissão, os primeiros contatos com a prática profissional, proporcionando-lhes uma visão geral dos fatores que podem influenciar o seu trabalho. $\mathrm{Na}$ atualidade, essa etapa da formação de professores "se configura como um espaço de interlocução mútua entre os formadores, estagiários e professores colaboradores, não sendo mais vista apenas como um espaço de prática para os futuros professores" (GIMENEZ; PEREIRA, 2007, p. 97). Desse modo, o estágio supervisionado é uma forma de diminuir a distância entre a teoria ensinada na graduação e a prática realizada pelos estagiários.

O estudo de Ortenzi (2005) mostra que há uma necessidade premente de proporcionar aos alunos-professores de inglês mais contato com a sala de aula e com o contexto escolar durante sua formação universitária. Para que isso ocorra, Cristovão (2005) e Gimenez e Pereira (2007) apontam o estabelecimento de parcerias entre universidade e escola que possam oportunizar, por meio de relaçôes colaborativas, o desenvolvimento profissional dos professorescolaboradores das escolas, dos professores-supervisores da disciplina de prática de ensino de inglês e dos alunos-professores. No entanto, segundo Perin (2005), o estágio supervisionado, na maioria dos cursos de formação, encontrase desarticulado do restante do curso. Desse modo, ela sugere que o estágio ocorra desde o início do curso de graduação, permeando toda a formação do futuro professor de inglês.

Dutra, Gimenez e Peres (2007) ressaltam que, na formação universitária de professores de inglês, discurso e prática são incoerentes, pois se diz ao alunoprofessor que ele deve elaborar projetos, refletir sobre sua prática, trabalhar colaborativamente, quando, na verdade, o que se pratica na universidade se mostra completamente desarticulado do que é ensinado nas escolas. As autoras propóem que a formação universitária aconteça "de forma colaborativa e em um contexto de comunidade de aprendizagem” (p. 72). Vieira-Abrahão (2002) também aponta para a importância de o estágio supervisionado ser desenvolvido em um ambiente de colaboração de modo a levar o alunoprofessor a refletir sobre sua prática. Segundo essa autora, o professorformador exerce um papel fundamental nesse desenvolvimento, pois a ele cabe dialogar com seu orientando "no sentido de estimular cada vez mais sua 
capacidade de localizar questões, compreendê-las e encontrar soluções e encaminhamentos" (p. 70).

Formar profissionais docentes capazes de refletir sobre a própria prática, investigando-a desde a realização do estágio supervisionado, parece ser condição sine qua non nos cursos de formação desde a década de 1990. No entanto, conforme salienta Zeichner (1992), há que se considerar as limitaçōes de algumas versões de estágio pautadas por uma epistemologia da prática, visto que, sob a alegação de estar fazendo mudanças, apenas legitimam "práticas que deveriam ser transformadas" (p. 127). Outro perigo, segundo o autor, é a rejeição de todo e qualquer conhecimento externo à sala de aula, ou seja, do conhecimento acadêmico científico. Além disso, corre-se o risco de refletir por refletir, sem considerar os "princípios morais e éticos que determinam o modo de pensar dos professores" (ZEICHNER, 1992, p. 128).

Descontadas as problemáticas apresentadas por Zeichner (1992), acreditamos que a prática proporcionada pelo estágio supervisionado deve se realizar em um ambiente em que professores de inglês em formação se beneficiem desse momento para compreender mais e melhor as diferentes realidades de ensino dessa língua nos variados contextos em que poderão atuar como docentes e que haja desenvolvimento profissional dos professorescolaboradores e dos professores-supervisores. Também creditamos à reflexão sobre a própria prática desde a formação universitária uma parcela importante na preparação dos futuros docentes para enfrentar os obstáculos inerentes ao início da carreira docente. Estendemos nossas considerações à realização de pesquisas reflexivo-críticas pelos professores em formação desde o início do curso de graduação, pois, comungando com Freire (1996/2007, p. 39), cremos que seja com rigorosidade metódica na análise crítica de ações anteriores ou atuais "que se pode melhorar a próxima prática".

\section{Ensino de inglês em escolas públicas}

Vários estudos sobre o ensino de inglês nas escolas públicas brasileiras têm sido desenvolvidos por diferentes pesquisadores, enfocando diversos aspectos desse contexto. Coelho (2006) trata das crenças de professores de inglês em escolas públicas de Minas Gerais sobre a possibilidade de aprender tal língua nesse tipo de escola. Os resultados encontrados pela autora mostram a necessidade de: 1) currículos que privilegiem conteúdos significativos para os alunos; 2) seriedade no ensino de inglês, possibilitando o conhecimento das quatro habilidades; e 3) ressignificação da escola com base nas propostas educativas apontadas pela legislação e por estudos recentes sobre tal assunto. 
O estudo de Pessoa (2006), cujo objetivo era examinar as reflexões de quatro professores de inglês de escolas públicas em Goiás sobre seu fazer pedagógico e as consequências desse fazer para os alunos, mostra que o questionamento da própria prática pelos professores participantes propiciou um redimensionamento de suas teorias práticas sobre o ensino de inglês na escola pública. Além disso, eles atestam que o movimento de mudança em suas práticas foi deflagrado pela oportunidade de olhar mais sistematicamente para tais práticas durante as sessões de reflexão das quais tomaram parte.

Perin (2003) apresenta a visão de professores e alunos da rede estadual de Maringá-PR sobre o ensino de inglês nas escolas públicas daquela cidade. Os resultados apontam uma realidade de ensino não muito diferente da que encontramos no Estado de Goiás, tanto no que tange ao ensino quanto à formação dos professores. Segundo a autora, o ensino de inglês ocorre em um processo cíclico de causa e efeito, em que a escola, que não pode interferir na contratação dos docentes, não se responsabiliza pela má atuação de alguns deles. Os professores, por sua vez, devido à falta de apoio profissional e financeiro por parte do governo, não se engajam no desenvolvimento de ações conjuntas para garantir uma aprendizagem mais efetiva. Os alunos e gestores das escolas, devido à grande rotatividade de professores, têm sempre a sensação de que não há progressão de conteúdos. Isso acarreta uma desvalorização tanto da disciplina quanto do trabalho do professor de inglês, gerando menos oferta de trabalho. No final, a frustração de todos os envolvidos no processo é patente. Revela-se, na conclusão da autora, uma crítica aos programas de formação de professores de língua inglesa e às propostas de ensino feitas pela legislação, pois, para ela, qualquer intervenção ou mudança na escola e na forma de ensinar inglês devem ter como base a cultura escolar e advir principalmente da prática de sala de aula.

A pesquisa de Uechi (2006) analisa cinco contextos diferentes de ensino de inglês nos níveis fundamental e médio em escolas públicas e privadas de São Paulo. A autora constatou que, em todos, a língua inglesa é vista como disciplina-problema e, por isso, foi tratada de modo diferenciado pelas escolas, que buscaram formas alternativas de ensiná-la: parcerias de uma escola particular e um centro de idiomas, a criação de um centro de línguas dentro de um dos colégios pesquisados, terceirização do ensino em outro, implantação de uma Disciplina-Projeto de ensino da língua-alvo para o ensino médio em uma escola pública e aulas de revisão para alunos do terceiro ano de escolas públicas, visando à leitura. Segundo a autora, as tentativas das escolas de 
solucionar o problema acabam por gerar um embate entre o novo e o tradicional no ensino de inglês. As escolas, na busca por propostas de ensino mais condizentes com modelos contemporâneos que possam tornar o ensino de inglês mais adequado e eficiente, se veem constrangidas por influências externas, como a alardeada necessidade de "domínio" da língua inglesa para fazer parte do mundo globalizado da atualidade e de adentrar mais facilmente o mercado de trabalho. O estudo também salienta a mercantilização do ensino de inglês que acaba por ocorrer diante das demandas globais e de comunidades locais.

Diante do exposto, percebe-se que, qualquer que seja a proposta pedagógica das escolas públicas, a intenção é tornar o ensino de inglês mais significativo para os alunos, diminuindo ou extinguindo a frustração tanto de professores quanto de alunos. Para tanto, faz-se necessário que o conhecimento dos professores seja considerado no momento da elaboração de currículos, pois eles conhecem mais profundamente a realidade na qual atuam. Além disso, a escola deve se ressignificar, de forma a atender à legislação para o ensino de inglês e aos interesses dos alunos, pais e mestres.

\section{Um contexto quase ideal}

Esta pesquisa foi realizada no Centro de Ensino e Pesquisa Aplicada ao Ensino (CEPAE) - aqui identificado com o intuito de valorizar e reconhecer o trabalho de estágio supervisionado de inglês ali desenvolvido -, instituição vinculada à Pró-Reitoria de Graduação da Universidade Federal de Goiás (UFG), numa turma de quinta série, com vinte alunos. O CEPAE mantém em funcionamento regular o Ensino Fundamental e o Ensino Médio, além de oferecer alguns cursos de pós-graduação lato sensu. O ensino de língua inglesa nessa instituição se baseia na Abordagem Comunicativa, uma vez que são focalizados sistematicamente aspectos funcionais e estruturais da língua (RICHARDS; RODGERS, 2001). Nas aulas, em geral, estruturas contextualizadas são apresentadas e praticadas em atividades comunicativas, envolvendo as quatro habilidades. A carga horária é de duas horas-aula semanais.

O período de estágio de língua inglesa realizado no CEPAE é composto de três etapas distintas: observação, semirregência e regência. Na primeira, os estagiários observam as ações do professor da turma por um mês, a fim de se ambientarem tanto com o funcionamento da sala de aula quanto com o método de ensino empregado. Na segunda fase, os estagiários começam a dar aulas em duplas e, cada um ministra, em média, duas horas-aula. A importância dessa fase consiste na possibilidade de o estagiário ganhar confiança. Na terceira 
e última fase, os estudantes em formação se ocupam em dar aulas inteiras (cerca de quatro horas-aula para cada um deles), tendo a oportunidade de lidar com a turma como se eles fossem professores da turma investigada. Ao final de cada uma das aulas, os estagiários se reúnem com o professor da turma para discutilas em sessóes de feedback, nas quais tanto o professor quanto os estagiários tecem comentários sobre as aulas do dia.

De um lado, se comparado às demais escolas públicas goianas, o CEPAE pode ser considerado um contexto ideal de ensino e de formação de professores, visto que seu quadro de professores é formado por mestres e doutores, que atuam única e exclusivamente em suas áreas de formação e, à exceção de um, em caráter de dedicação exclusiva. Além disso, eles são agrupados por subáreas (Língua Estrangeira, por exemplo) e áreas (Comunicação e Artes é um exemplo), facilitando o contato e o desenvolvimento de projetos de ensino. Os professores também participam ativamente das decisões pedagógicas e administrativas em reuniões mensais. Cada sala recebe, no máximo, 30 alunos, que adentram o sistema por meio de sorteio de vagas. Os professores de línguas (inglês, francês e espanhol) ministram suas aulas na língua-alvo para turmas de, no máximo, 20 alunos e em salas exclusivas aparelhadas com TV, DVD, vídeo cassete, aparelho de som e quadro branco. Há trabalhos com obras literárias, filmes, músicas etc., além de vários outros materiais pedagógicos de apoio. A escola ainda conta com biblioteca, rádio, sala de música, quadra de esportes, meliponário, laboratório de química e de informática, auditório, refeitório, sala de dança, entre outras facilidades.

Quanto à formação de professores, o CEPAE recebe alunos dos diferentes cursos de licenciatura da Universidade Federal de Goiás para a realização do estágio supervisionado. Há uma estreita relação entre a escola e a universidade, de modo que os professores-colaboradores não apenas recebem professores em formação, mas participam ativamente do processo de formação, observando, avaliando e orientando os alunos durante a realização do estágio.

Por outro lado, o CEPAE enfrenta problemas disciplinares, estruturais e de aprendizagem bastante semelhantes aos enfrentados pelas demais escolas públicas. Ainda que as aulas sejam ministradas na língua-alvo, a maioria dos alunos não alcança a proficiência linguística esperada. A desmotivação dos alunos nas aulas de línguas é um obstáculo a ser superado. O prédio necessita de reforma, bem como as carteiras, mesas e quadros. A grande quantidade de estagiários em uma mesma sala de aula, muitas vezes, impossibilita que o 
estágio supervisionado seja mais eficiente na formação desses futuros profissionais. Sendo assim, levando-se em conta os aspectos aqui apresentados, consideramos o CEPAE como um "contexto quase ideal" tanto para o ensino e a aprendizagem de inglês quanto para a realização do estágio supervisionado.

\section{Os participantes e os instrumentos de coleta de dados}

Participaram deste estudo quatro professores em formação universitária, estudantes da Faculdade de Letras/UFG com habilitação em Português e Inglês, que cursavam o quinto e último ano do curso ${ }^{1}$. As três professoras Laila, Laura e Luísa ainda não tinham vivenciado a experiência de serem professoras de inglês e o professor Pedro já lecionava há pelo menos oito anos em cursos livres de inglês.

Os dados foram coletados por meio de entrevistas semiestruturadas, realizadas no início (EI) e no final (EF) do período de coleta (abril a setembro de 2006). Tais entrevistas foram gravadas em áudio e transcritas de maneira não-verbatim. Optou-se pela adaptação das falas à norma padrão, pois o que interessava era o conteúdo e não a forma linguística. Além disso, um questionário (Q) foi enviado aos participantes via $e$-mail em novembro de 2008, quase dois anos após o término do curso, com o intuito de verificar se eles estavam atuando como professores de inglês na escola pública e se suas teorias pessoais sobre o ensino nesse contexto tinham sofrido alguma mudança.

\section{Falando do lugar de professores em formação}

$\mathrm{Na}$ entrevista inicial, de modo geral, a visão das três participantes sobre o ensino de inglês na escola pública é bem típica do professor recém-formado ou iniciante, configurando-se de modo bastante idealista. O idealismo se faz presente na vontade manifestada por elas de fazerem algo diferente do que suas professoras fizeram quando eram estudantes do Ensino Fundamental e Médio, como se pode ver no seguinte excerto:

[...] se for para eu escolher, eu gostaria de trabalhar em escolas públicas, porque eu tenho vontade de fazer diferente do que fizeram comigo. Diferente no sentido de dar oportunidade aos alunos de ter a esperança

\footnotetext{
${ }^{1} \mathrm{O}$ regime do curso ainda era o anual, portanto, somente no quinto e último ano de curso, os professores em formação faziam a disciplina de Didática e Prática de Ensino de Inglês e, consequentemente, o estágio supervisionado.
} 
de, realmente, aprender um pouquinho. Meu alvo é tornar o aprendizado da língua o mais próximo possível da realidade do aluno. Talvez, hoje, isso seja mais fácil, porque o contato com a mídia, com a informática está mais popularizado. Eu penso que é possível acender uma expectativa ou não apagar a expectativa daquele que acha que vai aprender. Eu gostaria que meus alunos aprendessem realmente. Eu não vou dizer sair falando inglês, mas que eles aprendessem e fosse útil para a vida deles, não fosse simplesmente uma matéria a mais. Eu tenho vontade de fazer essa diferença (Laila, EI, 12/05/2006).

Em meio a sua grande expectativa de fazer com que a língua inglesa seja útil na vida de seus futuros alunos, revela-se a teoria pessoal de Laila de que a tecnologia pode ajudar o professor a ensinar e o aluno a aprender a lingua-alvo. Essa sua teoria pessoal parece estar atrelada ao pensamento de muitos profissionais da educação, para quem ensino e aprendizagem somente se dão de modo efetivo se houver materiais tecnológicos envolvidos, descartando-se a possibilidade de que isso ocorra com o uso de pouca ou nenhuma tecnologia.

É bem verdade que Laila encontrará enormes desafios para cumprir seu objetivo de aproximar a aprendizagem de inglês da realidade de seus alunos. Entretanto, a oportunidade de refletir sobre os fatores que tornam difícil o ensino de línguas no contexto das escolas públicas brasileiras pode ser o caminho para que tal realidade seja mudada, uma vez que, por meio da reflexão, os futuros professores perceberiam o ensino de inglês de um modo mais realista - tendo consciência das limitaçóes e possibilidades a eles oferecidas-, o que causaria menos frustraçóes a esses docentes e talvez lhes desse mais força para continuar transformando sonhos em realidade.

A fala de Luísa revela sua teoria pessoal de que deve ser dada a oportunidade às crianças mais carentes de ter um ensino de inglês que seja realmente efetivo:

Não pretendo ensinar em escolas de idiomas não, mas em uma escola normal [escola regular e pública]. Principalmente, com crianças carentes. Eu fico vendo o trabalho da [professora da turma] e pensando quantas crianças não têm aquela oportunidade. Então, eu quero dar o melhor de mim para ver se eu levo isso para as crianças que realmente precisam, que não têm oportunidade (Luísa, EI, 11/05/2006).

Luísa não aponta dificuldades que possam impossibilitar suas ações. Ela parece perceber o ensino de inglês na escola pública como algo isento de problemas. Essa sua visão idealizada da realidade de tal contexto parece estar 
ligada a sua inexperiência como professora, o que a faz acreditar que o ensino de inglês na escola pública possa ocorrer sem maiores dificuldades e que, para isso, basta haver um professor disposto a realizá-lo de forma diferente. Assim como Laila, Luísa se mostra disposta a, pelo menos, tentar realizar tal tarefa.

Fruto da escola pública cujo foco da primeira lição de inglês é o verbo to be, Laura também quer atuar nesse contexto, com o intuito de ensinar inglês de um modo diferente:

Eu quero ir para a escola pública. Pelo que eu conheço, sabemos que, ainda hoje, a deficiência é muito grande. Eu quero tentar fazer alguma coisa na escola. Acho que é até porque foi onde eu sempre estudei. Então, é aquela coisa de você querer consertar, fazer alguma coisa que não fizeram com você. Então, eu quero ver se eu planto pelo menos uma sementinha, alguma coisa que seja diferente (Laura, EI, 04/05/2006).

Ao contrário de Luísa, que tem uma visão bastante idealista da escola pública, Laura percebe que há dificuldades inerentes ao ensino público, especialmente no que se refere à língua inglesa, que podem ser um entrave para a realização de um trabalho de qualidade. Todavia, ela parece não se intimidar diante das deficiências da escola pública. Assim como as demais participantes, ela está disposta a, pelo menos, tentar transpor os obstáculos que se apresentem, a fim de "fazer alguma coisa diferente". O "diferente", na concepção de Laura, Laila e Luísa, parece se referir a tornar a aprendizagem de inglês mais relevante para os alunos, levá-los a perceber que aprender outra língua pode ter alguma utilidade em suas vidas.

No excerto a seguir, pode-se notar a teoria pessoal de Laura de que $e ́$ possivel ensinar e aprender inglês na escola pública desde que alguns requisitos sejam observados:

Eu acho que não sei falar se dá para sair da escola usando as quatro habilidades. Acho que começando lá da quinta série [Ensino Fundamental] até o terceiro ano [Ensino Médio], tendo um livro e apoio, eu acho que é possível. Você pode ter um grande avanço, mas acho que do jeito que vai... não sei não... Acho que não existe ambiente propício ali para que isso aconteça. Eu acho que, por mais que você queira fazer diferente - e você pode fazer diferente -, eu não sei se vai. Agora, se compararmos uma aula de escola pública com o cursinho de inglês, eu acho que não dá. Acho que o resultado que você tem é bem diferente. Só que eu acho que se pode oferecer mais, melhorar mais. $\mathrm{Na}$ realidade, eu não sei se dá (Laura, EI, 04/05/2006). 
Os requisitos propostos na teoria pessoal de Laura se referem ao uso de livros didáticos, ao uso da língua-alvo tanto pelo professor quanto pelos alunos, desde as primeiras aulas nas séries iniciais até no último ano do Ensino Médio, e apoio, que entendemos como apoio pedagógico aos professores na realização da tarefa de ensinar a língua-alvo. Assegurados esses requisitos, ela acredita em avanços em relação ao que se faz na escola pública, mas não em mudanças profundas, pois percebe que tais mudanças precisam abranger não só a aula de inglês, mas a escola como um todo. Ao dizer que "não existe ambiente propício para isso", Laura nos leva a crer que essas mudanças devem alcançar as políticas públicas para o ensino de línguas estrangeiras.

A visão menos idealista de Laura sobre o ensino na escola pública também se revela no fato de ela perceber que a vontade do professor esbarra em uma série de obstáculos que, muitas vezes, acabam por suplantá-la, ao mesmo tempo em que mostra sua disposição e desejo de "fazer diferente". Nota-se aqui um embate entre acreditar na possibilidade de fazer diferente e as reais condições de realização desse intento. Além disso, o modo como Laura percebe o ensino público em oposição ao privado remete aos objetivos educacionais para a escola pública defendidos em Gimenez (2001). Segundo essa autora, a formação do estudante deve ser integral, de modo que ele possa "atuar e participar" do mundo em que vive. Portanto, a escola pública não deve se preocupar em atingir os mesmos padróes dos cursos de idiomas, que têm o objetivo instrumental de apenas ensinar os alunos a falar.

Pedro, guiado por sua teoria pessoal de que os métodos que se pautam pelo ensino comunicativo de linguas surtem mais efeito para o aprendizado dos alunos - revelada em outro momento da entrevista -, também fala em "fazer diferente", mas do lugar de quem não conhece esse contexto:

Pelo que ouço comentar, acho que deve ser meio difícil para o professor dar aula comunicativa, porque, "nossa, imagina quantos alunos tem ali dentro". Eu acho que seria difícil, mas eu ia tentar, pelo menos. A minha intenção é que, quando eu for dar aula, eu vou querer fazer uma coisa legal. Eu vou tentar. Agora, se eu não conseguir, aí... aí... Mas que eu vou tentar, eu vou. Eu vou chegar lá e vou fazer a minha parte. Eu vou tentar mudar, mas se não der certo... (Pedro, EI, 23/06/2006).

Pedro percebe a escola pública como um local em que é possível ensinar inglês de modo comunicativo. Suas falas acerca disso, no entanto, não parecem ingênuas, pois ele consegue perceber um dos entraves para a realização de aulas 
comunicativas nessas escolas: o grande número de alunos nas salas de aula. Mas, como todo profissional em início de carreira, ele idealiza essa possibilidade, dizendo que vai "tentar fazer a parte dele". No entanto, as duas hesitações presentes em sua fala - "se eu não conseguir, aí... aí... e "mas se não der certo..." - revelam a insegurança característica do professor iniciante, bem como um possível descrédito à possibilidade de ensinar e aprender inglês nas escolas públicas.

\section{Falando do lugar de professores recém-formados}

$\mathrm{Na}$ entrevista final, encerrados o estágio supervisionado e o curso de graduação, o ensino de inglês na escola pública passa a ser visto pelos participantes do lugar de professores que vivenciaram tal contexto, ainda que em uma escola quase ideal. Laila reafirma sua intenção de dar aulas na escola pública:

Continuo [querendo dar aulas na escola pública]. É claro que agora eu estou pensando que é muito mais difícil do que eu imaginava, porque, no início, eu pensava: "Ah, eu vou fazer a diferença, porque na escola pública todo mundo tem a ideia de que ninguém aprende inglês, mas também tem os professores que estão acomodados...”. Eu tinha esse olhar. Agora, parece que eu estou começando a cair na real, que a coisa não é fácil, que a escola pública não tem recursos, tem alunos demais, então, a realidade é muito difícil. Eu comecei a ver o outro lado da moeda. Mas, mesmo considerando que é complicado, eu ainda gostaria de tentar (Laila, EF, 21/11/2006).

Se na primeira entrevista Laila já percebia alguns dos entraves para um ensino efetivo de língua inglesa na escola pública, nesse excerto vê-se que ela se tornou mais consciente da realidade de muitas dessas escolas. "Começar a cair na real" sobre a verdadeira situação do ensino de inglês nas escolas púbicas parece ter sido causado pela observação da realidade do CEPAE, que, embora seja um contexto privilegiado conforme dito anteriormente, não deixa de ser uma escola pública que enfrenta problemas como indisciplina, pouca proficiência linguística de alguns alunos, falta de compromisso com a própria aprendizagem, falta de material didático, estrutura física sucateada, entre outros. A percepção desse outro lado do CEPAE associada às discussões realizadas nas sessões de feedback nos parece ser um fator que contribuiu para que Laila alterasse um pouco seu ponto de vista sobre a certeza de poder ensinar 
aos seus alunos de modo diferente do que foi ensinada. É importante ressaltar que, mesmo diante da constatação das dificuldades em ensinar a língua inglesa na escola pública, Laila não desistiu de atuar nesse contexto e nem de tentar de "fazer diferente".

Seis meses depois, Luísa permanece firme no propósito de ensinar na escola pública. Ela teoriza que a escola pública é o lugar para aplicar os conhecimentos adquiridos durante o estágio supervisionado e na graduação:

Continuo [querendo dar aula em escola pública] porque acredito que tudo o que a gente aprendeu aqui pode contribuir muito lá fora. Eu acho que a escola pública é um lugar ideal para você colocar em prática o que você aprendeu aqui, porque lá tem muita criança que precisa disso, precisa de mudança, precisa de mais atenção. E o que a gente aprendeu aqui é que temos de pensar mais no aluno, respeitar o momento de cada um, tentar passar tudo o que a gente aprendeu da melhor forma (Luísa, EF, 28/11/2006).

Luísa parece muito mais segura da possibilidade de ensinar efetivamente a língua inglesa na escola pública agora que tem o respaldo dos conhecimentos adquiridos tanto na graduação quanto no estágio supervisionado. Porém, sua teoria pessoal dá ideia de que tudo aquilo que é dado na universidade deve ser aplicado tal qual foi apresentado, como se o conhecimento acadêmico fosse uma verdade inquestionável. É óbvio que esse conhecimento é importante, mas, em vez de "aplicado", deveria ser utilizado, por ela, como subsídio para elaboração ou reestruturação das próprias teorias pessoais acerca de sua prática pedagógica.

Ao mesmo tempo em que acredita na possibilidade de ensinar e aprender inglês nas escolas públicas, Laura, diante das dificuldades que sabe que irá enfrentar, não se sente completamente segura para fazer dessa sua ideia uma asserção positiva. A sua incerteza aponta para uma conscientização de que exercer a docência de língua inglesa em escolas públicas não será trabalho fácil e demandará disposição para realizá-lo a contento dos alunos, dos pais, da comunidade e da escola, sem deixar de lado os interesses do professor. Perguntada sobre seu desejo de atuar na escola pública na segunda entrevista, Laura afirma que tal intento permanece, bem como a ideia de "fazer diferente". Mas, por outro lado, Laura percebe que, para "fazer diferente", ela precisa agir diferente. Sua teoria pessoal no seguinte excerto é a de que ensinar inglês na escola pública significa conhecer a realidade do aluno para fazer algo diferente: 
Quero atuar na escola pública, mas eu não espero nada fácil. Eu sei que a questão da indisciplina deve ser bem maior, porque são crianças que tem mais problemas, que vivem outra realidade. A primeira coisa que eu quero fazer é me engajar no mundo deles e, daí, tentar alguns planos, alguma direção que eu possa caminhar junto com eles. Não quero aquela coisa de passar o verbo to be e ficar só naquilo. De repente, promover mais para eles. Levar uma tirinha, uma coisa diferente, na qual tenha uma palavra ou uma situação diferente, para eles terem a possibilidade de ter um contato melhor com a língua e de aprender (Laura, EF, 24/11/2006).

Pode-se dizer que a teoria pessoal de Laura sobre o ensino e a aprendizagem de inglês na escola pública reside no engajamento do professor ao mundo do aluno, realizando aulas em que a realidade do aluno seja privilegiada, proporcionando-lhes um contato mais produtivo com a línguaalvo, de modo que a aprendizagem da língua em questão seja relevante para o estudante. Ao dizer que não espera nada fácil e falar da questão da indisciplina, Laura mostra que tem uma ideia das dificuldades que enfrentará no contexto da escola pública. Mas, é interessante notar que, mesmo diante dessa constatação, ela aponta para uma prática diferenciada, comungando com uma série de preceitos propostos por Freire (1996/2007), pois ela pretende que o conhecimento seja coconstruído com seus alunos.

$\mathrm{Na}$ segunda entrevista, Pedro continuava querendo ser professor de inglês na escola pública:

Prefiro dar aula em escola pública do que em escola particular, porque eu acho que, na escola particular, tem muita autoridade em cima de você. Acho que eles são mais tradicionalistas. Eu já acho que, na escola pública, não. A gente tem mais liberdade para ensinar do que em escola particular (Pedro, EF, 04/12/2006).

A teoria pessoal de Pedro revelada nesse excerto de que a escola particular, por utilizar métodos mais tradicionais, é mais controladora, ao passo que, na escola pública, o professor é livre para usar os métodos que julgar necessários à aprendizagem dos alunos aponta para uma visão mais crítica das possibilidades de ação do professor naquele ambiente. Ou seja, na visão de Pedro, a escola pública não se mostra um ambiente tão controlador das ações do professor como querem nos fazer acreditar alguns desses profissionais, que se escondem sob essa ideia de controle para continuar com as mesmas práticas arcaicas de ensino. Diante dessa pressuposta liberdade de ação do professor de inglês da 
escola pública, reforça-se a ideia de poder "fazer diferente" do que comumente se faz. No caso de Pedro, "o diferente" reside na utilização de novos métodos ou propostas pedagógicas, mais especificamente, do ensino comunicativo de línguas.

\section{Falando do lugar de professores iniciantes}

No questionário enviado aos participantes em novembro de 2008, foram constatadas algumas mudanças em suas teorias pessoais sobre a possibilidade de ensinar inglês na escola pública.

Laura, apesar de ainda estar na sala de aula, afirma que se desilude a cada dia com o ensino na escola pública e que pretende sair assim que passar em um dos concursos para os quais tem estudado:

Desde que saí da faculdade, estou lecionando em escola pública. Hoje, eu não tenho o desejo de continuar dando aula. Estou estudando para concurso e esperando que novas oportunidades apareçam na minha vida. $\mathrm{O}$ meu entusiasmo pela educação está diminuindo. É algo que não me alegra, pois em alguns momentos tenho a sensação de que deveria ter feito tudo diferente e que poderia ter tentado outros rumos para minha vida profissional. Há momentos, na sala de aula, em que me sinto desanimada e perdida, pois parece que não basta preparar aula, pesquisar atividades e ter envolvimento com seu trabalho. Tudo isso parece em vão quando ficamos falando e os alunos não dão ouvidos ao trabalho proposto. Outro grande agravante é a indisciplina, a violência e a desvalorização por todos da escola pública (Laura, Q, 22/ $11 / 2008)$.

O desânimo de Laura após tão curto período como professora de inglês na escola pública já se evidenciava, no final do estágio supervisionado, quando a entrevistamos. A diminuição de seu entusiasmo pela educação nos leva a questionar a validade dos cursos de formação no que tange a preparação de professores para enfrentarem a complexa e conturbada realidade da maioria das escolas públicas. Muitos desses cursos se preocupam em fornecer variadas técnicas de ensino aos seus alunos, deixando de abordar aspectos como o relacionamento aluno / professor, a questão da violência presente em muitas escolas, a desvalorização que a profissão vem sofrendo ao longo dos anos, a autoestima e a motivação do professor, entre outros.

Ao contrário de Laura, Luísa continua acreditando no ensino de inglês na escola pública: 
Eu estava lecionando Português na entidade "Sociedade Cidadão 2000" como substituta, mas meu contrato venceu e, infelizmente, meus planos para continuar trabalhando lá, agora, provavelmente, como professora titular de inglês, foram por água abaixo. Eu devo ser convocada, em breve, para assumir na prefeitura, pois meu nome é o próximo da lista. Eu estava amando trabalhar na CAT (Coordenação do Adolescente Trabalhador). Lá, eu tive a oportunidade de conhecer de perto o trabalho com esses jovens e participar diretamente das atividades da equipe pedagógica. É uma pena que tudo não possa continuar como antes, pois o trabalho com esses adolescentes é mesmo indispensável. Eu ainda continuo com o mesmo pensamento e fico muito feliz quando sinto que estou sendo útil em uma escola pública. Não sei o dia de amanhã, mas pretendo continuar com o meu propósito de sempre (Luísa, Q, 28/11/2008).

A teoria pessoal de Luísa de que as crianças carentes realmente precisam de oportunidade de aprender inglês de modo diferenciado permaneceu inalterada. O seu entusiasmo pelo ensino na escola pública continua o mesmo, conforme ela mesma atesta. $\mathrm{O}$ fato de ter vivenciado a dura realidade das crianças atendidas pelo programa de assistência por ela mencionado e de ainda não ter atuado como professora de inglês não arrefeceu seu desejo de ensinar de maneira diferente da qual foi ensinada. Ao contrário, o conhecimento das dificuldades parece ter sedimentado sua vontade e acrescentado o desejo de realizar um trabalho no âmbito social com as crianças e adolescentes participantes do programa "Sociedade Cidadão 2000".

Laila também se mostra motivada para continuar a ensinar inglês na escola pública a despeito da confirmação de algumas dificuldades mencionadas por ela anteriormente:

Estou lecionando em uma escola da rede municipal de ensino. Trabalhei com português por um ano e meio na rede particular, mas agora estou fazendo o que eu realmente queria: lecionando inglês em escola pública. Comecei a atuar assim que terminei o curso da faculdade. Como professora de inglês, comecei em jan/2008. Não mudei de ideia quanto a ensinar em escola pública. Continuo querendo fazer a diferença na vida dos meus alunos em relação ao ensino da língua inglesa. Entretanto, esse quase um ano de experiência me fez constatar algumas dificuldades que eu já previra, como salas cheias e falta de recursos, às quais eu hoje somaria outras, tais como minhas próprias limitações devido à inexperiência e mesmo personalidade, que acentua o problema de indisciplina; peguei alunos que já estavam 
acomodados a não aprender, o que está associado a um sistema $\left(\operatorname{ciclos}^{2}\right)$, que, na minha opinião, não é bom, pois não apresenta desafios aos alunos e os aprova sem que eles tenham conhecimento suficiente. Diante desse tipo de mentalidade, fiquei um pouco frustrada, mas ainda não desisti, e espero que a experiência me traga soluções para essas dificuldades e não o comodismo que tenho visto em alguns colegas veteranos (Laila, Q, 02/12/2008).

Como se vê, Laila continua a acreditar na possibilidade de ensinar inglês na escola pública. A confirmação de algumas dificuldades e a constatação de outras não parecem ter sido suficientes para provocar mudanças em suas teorias pessoais. É interessante ressaltar que ela divide a responsabilidade por tais dificuldades entre ela, os alunos e o sistema escolar, caracterizando uma visão mais ampla dos fatores que interferem em seu trabalho como professora, ao contrário da visão reducionista da maioria dos professores iniciantes, que tende a excluir sua atuação da lista de fatores que interferem no processo de ensino e aprendizagem.

O participante Pedro continua acreditando no emprego do ensino comunicativo de línguas nas escolas públicas:

Eu não estou lecionando no momento. Fiquei seis meses em uma escola da prefeitura, e estava gostando. Eu estava lecionando no EAJA [Educação para Adolescentes, Jovens e Adultos]. Estava fazendo um bom trabalho. Não dava pra fazer a mesma coisa que eu fazia no CEPAE, aquela aula em inglês do Communicative Approach. Eu até que tentei, mas acabei desistindo. Na minha opinião, há toda uma questão cultural e social que não permite que os professores da rede pública realizem esse trabalho com o Communicative. Os alunos não estão preparados pra isso, porque já foram moldados, condicionados pelos professores anteriores de maneira diferente, e não conseguem se adaptar. Eu, então, passei a mesclar as aulas com inglês e português, mas não abri mão dos passos e das atividades do Communicative, apesar de que os idosos muitas vezes se recusavam a fazer a parte oral, e

\footnotetext{
${ }^{2}$ Organização do Ensino Fundamental em conformidade com as fases do desenvolvimento humano - infância, pré-adolescência e adolescência. Ensinar conforme esse modelo implica uma flexibilização dos processos avaliativos, do currículo escolar, da organização do trabalho e da gestão da escola. Em Goiânia, o Ensino Fundamental se divide em quatro ciclos de dois anos, tendo como principal critério a faixa etária do educando. Essa proposta de ensino se baseia principalmente nas ideias de Vigostky, Piaget e Paulo Freire.
} 
acabavam por escrever os diálogos da practice. Eu acho que todo o sistema educacional público, pelo menos na área de Língua Estrangeira, precisa ser reformulado, conscientizando alunos e professores quanto ao método comunicativo, para que este possa ser desenvolvido e aplicado por todos os docentes. Mesmo porque a maioria dos professores de inglês mal fala a língua e nunca ouviu falar do Communicative (Pedro, Q, 25/11/2008).

Pedro tentou, ainda que com várias limitações, ensinar inglês na escola pública utilizando o método comunicativo, em que ele tanto acredita. A sua crença no ensino comunicativo de línguas, diante dos bons resultados alcançados no período em que lecionou naquela escola, parece ter se reforçado mais ainda, pois ele aventa a necessidade de que todo o sistema educacional público e os professores de língua estrangeira - não só os de inglês - se guiem por esse tipo de ensino. Pedro acredita que assim os resultados seriam muito mais satisfatórios.

\section{Considerações finais}

Os participantes deste estudo teorizam sobre o ensino de inglês na escola pública antes e depois da realização do estágio. As participantes Laila, Laura e Luísa, inicialmente, percebem o estágio do lugar de alunas oriundas da escola pública e, ao final, do lugar de professoras que acabaram de se formar e que pretendem dar aulas nesse tipo de instituição de ensino. Já o participante Pedro, de início, entende o ensino de língua inglesa nas escolas públicas do lugar de quem já ouviu falar sobre ele, visto que, tendo estudado apenas em escolas privadas, não podia fazê-lo sob a ótica de aluno. No final do processo de estágio supervisionado, a visão de Pedro se desloca para o lugar de professor formado que vivenciou, no CEPAE, uma das possíveis realidades de escola pública.

O estágio supervisionado parece ter influenciado pequenas mudanças nas visões dos participantes Pedro, Laila e Laura sobre o ensino de inglês em escola pública, visto que, ao final, eles apontavam dificuldades ou entraves para a realização de um ensino diferenciado em tal instituição de ensino, que não tinham sido mostrados antes. Ressalvadas as pequenas mudanças na visão dos participantes sobre ensinar inglês na escola pública, todos acreditavam, ao final do estágio supervisionado, que poderiam contribuir para que o ensino dessa língua se tornasse mais significativo para os alunos.

Acreditamos que a realização do estágio supervisionado no CEPAE contribuiu para que os estagiários se mantivessem firmes em seus propósitos 
de ensinar inglês em escolas públicas porque ali eles puderam refletir com seus pares sobre suas ações, além de terem a ajuda da professora-orientadora e do professor-supervisor com suas dúvidas, dificuldades e limitaçóes. Esse apoio, mais os conhecimentos teóricos adquiridos no curso, parece ter dado aos participantes mais certeza de querer atuar como professores de inglês na escola pública.

É esse contexto colaborativo que deveria ser criado nas escolas públicas entre os estagiários e os professores dessas escolas, mas um dos entraves é que elas não estão preparadas física e profissionalmente para receber os estagiários. $\mathrm{Na}$ maioria das vezes, os estagiários são vistos como uma ameaça pelos professores que os receberão em suas salas de aula, não havendo uma integração entre os objetivos da universidade e dessas escolas para o estágio supervisionado. Sendo assim, pensamos que os cursos de formação de professores, antes de enviar seus alunos a escolas públicas municipais e estaduais, devem buscar uma aproximação com essas instituiçōes, de forma que os professores-colaboradores participem mais ativamente do processo de formação dos futuros professores que receberão, como ocorre no CEPAE.

Diante disso, fica-nos a dúvida se a vontade de ensinar na escola pública demonstrada pelos participantes permaneceria a mesma, caso o período de prática tivesse se dado em escolas da rede pública do estado ou do município, visto que, nessas escolas, os estagiários dificilmente encontrariam o respaldo que encontraram no CEPAE. Esse é um questionamento que não poderemos responder, mas foi possível verificar se as teorias pessoais dos participantes sobre ensinar inglês na escola pública permaneceram as mesmas ou se sofreram mudanças após terem iniciado suas carreiras como professores em tal contexto. Três deles - Luísa, Laila e Pedro - permanecem com o mesmo intento e procuram fazer com que seus discursos e ações sejam coerentes na tentativa de ensinar inglês na escola pública. Laura, que já se mostrava um pouco reticente ao final de 2006, desiludiu-se completamente com o ensino de inglês e está tentando mudar de carreira.

Com base nos resultados deste estudo, cremos que o estágio deve continuar a ser realizado no CEPAE, pois, conforme apontado anteriormente, o trabalho ali desenvolvido contribui imensamente para a formação de futuros docentes de inglês. No entanto, ressalvamos que se deve dar aos estagiários a oportunidade de conhecer outros contextos de ensino de língua inglesa, passando por cursos de idiomas e indo até escolas públicas do centro ou da periferia da cidade. Conhecendo um pouco de cada possível contexto de 
atuação, pressupomos que os professores recém-formados poderão escolher com mais segurança o seu campo de atuação e, assim, conseguir realizar um trabalho mais satisfatório tanto para eles mesmos quanto para os alunos, a escola, os pais e a comunidade na qual atuarão.

\section{Referências}

COELHO, H. S. H. É possível aprender inglês na escola? - crenças de professores sobre o ensino de inglês em escolas públicas. In: BARCELOS, A. M. F.; VIEIRA-ABRAHÃO, M. H. (Org.). Crenças e ensino de línguas - foco no professor, no aluno e na formação de professores. Campinas: Pontes, 2006. p. 125-143.

CRISTOVÃO, V. L. L. Por relações colaborativas entre universidades e escolas. In: CRISTOVÃO, V. L. L.; GIMENEZ, T. (Org.). ENFLOPI - construindo uma comunidade de formadores de professores de inglês. Londrina: [s.n.], 2005. p. 19-22.

DUTRA, A.; GIMENEZ, K. M. P.; PERES, H. M. M. Conhecimentos em construção: uma análise de sessões de supervisão de prática de ensino de língua inglesa. In: GIMENEZ, T. (Org.). Tecendo as manhäs: pesquisa participativa e formação de professores de inglês. Londrina: Fundação Araucária, 2007. p. 63-72. FREIRE, P. Pedagogia da autonomia. São Paulo: Paz e Terra, 2007/1996.

GIMENEZ, T. A formação de professores de Inglês: desafios da próxima década. Boletim Centro de Letras e Ciências Humanas (UEL), v. 40, p. 9-16, 2001.

GIMENEZ, T.; PEREIRA, F. M. Relação universidade / escola na formação de professores de inglês: primeiras aproximações. In: GIMENEZ, T. (Org.). Tecendo as manhãs: pesquisa participativa e formação de professores de inglês. Londrina: Fundação Araucária, 2007. p. 97-111.

HANDAL, G.; LAUVAS, P. Promoting reflective teaching. Milton Leynes, UK: Open University Press, 1987.

ORTENZI, D. I. B. G. A dimensão prática da formação de professores de inglês. In: CRISTOVÃO, V. L. L.; GIMENEZ, T. (Org.). ENFLOPI - construindo uma comunidade de formadores de professores de inglês. Londrina: [s.n.], 2005. p. $15-18$.

PERIN, J. O. R. Ensino / aprendizagem de inglês em escolas públicas: um estudo etnográfico. Acta Scientiarium: human and social sciences, v. 5, n. 1, p. 113-118, 2003. 
PERIN, J. O. R. A articulação teoria / prática na formação de professores de inglês. In: CRISTOVÃO, V. L. L.; GIMENEZ, T. (Org.). ENFLOPI construindo uma comunidade de formadores de professores de inglês. Londrina: [s.n.], 2005. p. 23-27.

PESSOA, R. R. Reflexão interativa: desvelando e transformando teorias práticas sobre o ensino de inglês na escola pública. Trabalhos em Linguística Aplicada, v. 45, p. 75-86, 2006.

RICHARDS, J. C.; RODGERS, T. Approaches and Methods in Language Teaching. 2. ed. Cambridge-UK: Cambridge University Press, 2001.

UECHI, S. A. Inglês: disciplina-problema no ensino fundamental e médio? 2006. 175 f. Dissertação (Mestrado em Letras) - Faculdade de Filosofia, Letras e Ciências Humanas, Universidade de São Paulo, São Paulo, 2006.

VIEIRA, F. Pontes (in)visíveis entre teoria e prática na formação de professores. Curriculo sem Fronteiras, v. 5, n. 1, jan/jun 2005, p. 116-138.

VIEIRA-ABRAHÃO, M. H. Teoria e prática na formação pré-serviço do professor de língua inglesa. In: GIMENEZ, T. (Org.). Trajetórias na formação de professores de linguas. Londrina: UEL, 2002. p. 59-76.

VIEIRA-ABRAHÃO, M. H. Crenças, pressupostos e conhecimentos de alunosprofessores de língua estrangeira e sua formação inicial. In: VIEIRA-ABRAHAO, M. H. (Org.). Prática de ensino de língua estrangeira - experiências e reflexões. Campinas-SP: Pontes/Artelíngua, 2004. p. 131-152.

ZEICHNER, K. Novos caminhos para o practicum: uma perspectiva para os anos 90. In: NÓVOA, A. (Org.). Os professores e a sua formação. Lisboa: Dom Quixote, 1992. p. 115-138.

ZEICHNER, K. M.; LISTON, D. P. Reflective teaching: an introduction. New Jersey: Lawrence Erlbaum Associates, 1996.

Recebido em 22/04/09. Aprovado em 12/08/09. 